\title{
Analysis of TNF- $\alpha$ and interleukin- 6 in seroma of patients undergoing mastectomy with or without flap fixation: is there a predictive value for seroma formation and its sequelae?
}

Citation for published version (APA):

van Bastelaar, J., Granzier, R., van Roozendaal, L. M., van Kuijk, S. M. J., Lerut, A., Beets, G., Hadfoune, M., Damink, S. O., \& Vissers, Y. L. J. (2019). Analysis of TNF- $\alpha$ and interleukin-6 in seroma of patients undergoing mastectomy with or without flap fixation: is there a predictive value for seroma formation and its sequelae? Surgical Oncology, 28, 36-41. https://doi.org/10.1016/j.suronc.2018.11.001

\section{Document status and date: \\ Published: 01/03/2019}

DOI:

10.1016/j.suronc.2018.11.001

Document Version:

Publisher's PDF, also known as Version of record

\section{Document license:}

Taverne

\section{Please check the document version of this publication:}

- A submitted manuscript is the version of the article upon submission and before peer-review. There can be important differences between the submitted version and the official published version of record. People interested in the research are advised to contact the author for the final version of the publication, or visit the DOI to the publisher's website.

- The final author version and the galley proof are versions of the publication after peer review.

- The final published version features the final layout of the paper including the volume, issue and page numbers.

Link to publication

\footnotetext{
General rights rights.

- You may freely distribute the URL identifying the publication in the public portal. please follow below link for the End User Agreement:

www.umlib.nl/taverne-license

Take down policy

If you believe that this document breaches copyright please contact us at:

repository@maastrichtuniversity.nl

providing details and we will investigate your claim.
}

Copyright and moral rights for the publications made accessible in the public portal are retained by the authors and/or other copyright owners and it is a condition of accessing publications that users recognise and abide by the legal requirements associated with these

- Users may download and print one copy of any publication from the public portal for the purpose of private study or research.

- You may not further distribute the material or use it for any profit-making activity or commercial gain

If the publication is distributed under the terms of Article 25fa of the Dutch Copyright Act, indicated by the "Taverne" license above, 


\title{
Analysis of TNF- $\alpha$ and interleukin- 6 in seroma of patients undergoing mastectomy with or without flap fixation: is there a predictive value for seroma formation and its sequelae?
}

\author{
J. van Bastelaar ${ }^{\mathrm{a}, *}$, R. Granzier ${ }^{\mathrm{a}}$, L.M. van Roozendaal ${ }^{\mathrm{a}}$, S.M.J. van Kuijk ${ }^{\mathrm{b}}$, A.V. Lerut ${ }^{\mathrm{a}}$, G. Beets ${ }^{\mathrm{c}, \mathrm{d}}$, \\ M. Hadfoune ${ }^{\mathrm{e}}$, S. Olde Damink ${ }^{\mathrm{e}, \mathrm{f}}$, Y.L.J. Vissers ${ }^{\mathrm{a}}$ \\ ${ }^{a}$ Department of Surgery, Zuyderland Medical Center Sittard, the Netherlands \\ ${ }^{\mathrm{b}}$ Department of Clinical Epidemiology and Medical Technology Assessment, Maastricht University Medical Center, Maastricht, the Netherlands \\ ${ }^{\mathrm{c}}$ Department of Surgery, Netherlands Cancer Institute, Amsterdam, the Netherlands \\ ${ }^{\mathrm{d}}$ GROW School for Oncology and Developmental Biology, University of Maastricht, Maastricht, the Netherlands \\ ${ }^{\mathrm{e}}$ Department of Surgery, NUTRIM School of Nutrition and Translational Research in Metabolism, University of Maastricht, Maastricht, the Netherlands \\ ${ }^{\mathrm{f}}$ Department of General, Visceral and Transplantation Surgery, RWTH University Hospital Aachen, Aachen, Germany
}

\section{A R T I C L E I N F O}

\section{Keywords:}

Mastectomy

Seroma formation

Cytokines

IL-6

TNF- $\alpha$

\begin{abstract}
A B S T R A C T
Background: Seroma formation is a common complication after mastectomy. Flap fixation has the potential to prevent seroma formation, but identifying patients that are at risk of developing seroma, remains challenging. The aim of this study was to assess the association between pro-inflammatory cytokines in seroma fluid one day after surgery and seroma formation and it sequelae.

Methods: Patients undergoing mastectomy were randomized into one of three groups: no flap fixation, flap fixation using sutures or flap fixation using tissue glue. Seroma samples from 40 consecutive patients undergoing mastectomy were collected on the first postoperative day for analysis of interleukin- 6 and tumor necrosis factor$\alpha$. Seroma formation and its sequelae were assessed in the outpatient clinic ten days, six weeks and three months after surgery.

Results: TNF- $\alpha$ concentrations were not detectable in the seroma samples of any of the 40 patients. BMI $(p=0.001)$ and weight of the resected surgical specimen $(p=0.003)$ were associated with higher IL- 6 levels in seroma on the first postoperative day after mastectomy. A higher seroma concentration of IL- 6 was associated with significantly fewer patients with clinical seroma formation three months after surgery $(\mathrm{p}=0.027)$.

Conclusion: IL- 6 is associated with clinical seroma formation three months after surgery. There is however no evident association between IL- 6 and complications related to seroma formation. Higher IL- 6 levels are predictive of less long-term seroma formation. Application of flap fixation does not seem to influence the level of IL6.
\end{abstract}

\section{Introduction}

Seroma formation following mastectomy remains a frequent and persistent problem in breast cancer surgery. Many see it as a surgical nuisance rather than as being an avoidable surgical complication. Seroma formation can lead to (frequent) seroma aspirations, infection, skin flap necrosis, secondary surgical interventions, repeated outpatient visits and even delay in instituting adjuvant treatment [1-3]. It is suspected that patients suffering from seroma and its sequelae have a lower quality of life and that patients and society are confronted with higher costs [4].

Many articles have been published on techniques for reducing seroma formation and its complications [4-12]. The key to achieving this goal lies in reduction of the dead space [13], but closure of the dead space unfortunately does not guarantee a seroma free recovery. Certain factors have been associated with seroma formation, such as extent of

\footnotetext{
* Corresponding author. Zuyderland Medical Center, Henri Dunantstraat 5, 6419 PC, Heerlen, the Netherlands.

E-mail addresses: j.vanbastelaar@zuyderland.nl (J. van Bastelaar), r.granzier@zuyderland.nl (R. Granzier), l.vanroozendaal@zuyderland.nl (L.M. van Roozendaal), sander.van.kuijk@mumc.nl (S.M.J. van Kuijk), a.lerut@zuyderland.nl (A.V. Lerut), g.beets@nki.nl (G. Beets), m.hadfoune@maastrichtuniversity.nl (M. Hadfoune), steven.oldedamink@maastrichtuniversity.nl (S. Olde Damink), y.vissers@zuyderland.nl (Y.L.J. Vissers).
} 


\section{List of abbreviations;}

BMI body mass index

CON conventional wound closure

DCIS ductal carcinoma in situ

FF-S Flap fixation using sutures
FF-G

IL-6

MRM

SNLB

SSI

TNF- $\alpha$ tumor necrosis factor alpha surgical procedure, axillary clearance, use of electrocautery, smoking and BMI $[1,6,14]$. It is, however, not yet possible to accurately predict which patients are at risk for developing seroma and its sequelae.

Interleukin-6 (IL-6) and tumor necrosis factor- $\alpha$ (TNF- $\alpha$ ) are released by leucocytes that extravasate out of blood vessels [15-17]. They are crucial in initiating, controlling and terminating the cellular events of wound healing. These two cytokines can induce the production of proteases, elastases and matrix metalloproteinases [18]. Levels of proinflammatory cytokines in wounds or wound fluid can potentially be used as a reliable marker of tissue damage [19,20]. IL-6 has previously been shown to be an early marker of the systemic inflammatory response and tissue damage in patients undergoing mastectomy [21-23]. Previous studies have shown a relationship between pro-inflammatory cytokines in seroma and seroma formation [24], but no studies thus far have shown an association between IL- 6 and TNF- $\alpha$ levels and postoperative complications related to seroma formation after mastectomy. Seroma formation is associated with the extent of the surgical procedure and therefore seems to be related to tissue trauma. Pro-inflammatory cytokines such as IL- 6 and TNF- $\alpha$ are related to tissue damage; one could expect that patients with higher levels of the early systemic inflammatory response markers in seroma would also suffer from increased seroma formation. The aim of this study was to assess if there was any association between IL- 6 and TNF- $\alpha$ levels in seroma fluid measured on the first postoperative day and seroma and seroma related complications in patients undergoing mastectomy with or without flap fixation.

\section{Methods}

The Seroma reduction After Mastectomy (SAM) Trial is a double blind randomized controlled trial evaluating seroma formation and its sequelae in patients undergoing mastectomy with or without flap fixation. (https://clinicaltrials.gov/ct2/show/NCT03305757). A subgroup analysis was performed within this trial in 40 consecutive patients in order to perform IL- 6 and TNF- $\alpha$ analyses. Patients were allocated to one of three groups, (A) no flap fixation and placement of a low suction drain (CON), (B) flap fixation using sutures and placement of a low suction drain (FF-S), (C) flap fixation using ARTISS tissue glue and placement of a low suction drain (FF-G).

All participants were recruited from a large breast cancer clinic (Zuyderland Medical Center, Sittard-Geleen, the Netherlands) treating 500 newly diagnosed breast cancer patients annually. Female patients older than 18 years of age suffering from invasive breast cancer or ductal carcinoma in situ (DCIS) with an indication for mastectomy with or without sentinel lymph node biopsy (SNLB) or modified radical mastectomy (MRM), were eligible for inclusion. Patients undergoing breast conserving therapy or direct breast reconstruction or patients unable to sign for informed consent were not eligible for inclusion.

Randomization was achieved during surgery using a web based randomization programme $30 \mathrm{~min}$ before wound closure. Patients were blinded throughout the trial and the surgeon performing the follow-up assessments was also blinded.

Five experienced breast surgeons performed all procedures. All patients received $2 \mathrm{~g}$ of cefazolin prior to surgery. The nipple-areola complex was removed and dissection of the skin flaps was performed using electrocautery. Removal of breast tissue from the pectoral muscle included removal of the pre-pectoral fascia. All patients received a low suction drain before closure of the skin.

\subsection{Conventional wound closure}

After mastectomy and placement of a low suction drain, the extent of the skin flaps was measured (in cm's) from medial to lateral and from cranial to caudal. The skin edges were sutured using absorbable monofilament sutures (Monocryl 3.0 or V-loc $30 \mathrm{~cm}$ ), depending on the surgeon's preference.

\subsection{Flap fixation using sutures}

After mastectomy and placement of a low suction drain, the extent of the skin flaps was measured (in cm's) from medial to lateral and from cranial to caudal. The skin flaps were sutured on to the pectoral muscle using interrupted polyfilament absorbable sutures (Vicryl 3.0), placed at 4-5 cm intervals in two or three rows, depending on the extent of the skin flaps. The distance between all sutures was $4-5 \mathrm{~cm}$. Care was taken to prevent dimpling of the skin. The number of rows and total number of Vicryl sutures were noted. The axillary area was not approximated using sutures. The skin edges were sutured using absorbable monofilament sutures (Monocryl 3.0 or V-loc $30 \mathrm{~cm}$ ), depending on the surgeon's preference.

\subsection{Flap fixation using ARTISS tissue glue}

After mastectomy and placement of a low suction drain, the extent of the skin flaps was measured (in cm's) from medial to lateral and from cranial to caudal. ARTISS tissue glue (Baxter Healthcare, Australia) [25] was applied as a $2 \mathrm{~mL}$ spray and used on both skin flaps. Care was taken to make sure that the skin flap and pectoral muscle surfaces were dry before application of the glue. After the spray had been applied, compression on both skin flaps to the underlying muscle was applied for $3 \mathrm{~min}$. The skin edges were sutured using absorbable monofilament sutures (Monocryl 3.0 or V-loc $30 \mathrm{~cm}$ ), depending on the surgeon's preference.

\subsection{Drains}

The drain was connected to a low suction drain bottle and drain output was noted daily. In patients undergoing mastectomy without axillary clearance, the drain was removed when drain output was less than $50 \mathrm{~mL}$ or after a maximum of $48 \mathrm{~h}$, irrespective of drain output. In patients undergoing modified radical mastectomy (including axillary clearance) the drain was removed if daily production was less than $50 \mathrm{~mL}$ or after a maximum of 5 days, irrespective of drain output.

\subsection{Interleukin-6 and TNF- $\alpha$ sampling}

Seroma samples were collected on the first postoperative day for analysis of IL- 6 and TNF- $\alpha$. Drain fluid $(10 \mathrm{ml})$ was collected between 8 and 10 a.m. and the samples were consequently centrifuged at 1300 revolutions per minute for $10 \mathrm{~min}$ and stored at $-80^{\circ} \mathrm{C}$. IL- 6 and TNF- $\alpha$ concentrations were determined using in-house developed standard enzyme linked immunosorbent assays (ELISA). The sampling was performed in one batch to ensure reliability of the sampling process. 


\subsubsection{IL-6 ELISA}

A 96-well microplate (Greiner, 655061) was coated overnight at $4{ }^{\circ} \mathrm{C}$ with mouse anti-human IL6 (5E1). Hu IL-6 (R\&D Systems) was used for standard titration curve. Standard and samples were incubated for $2 \mathrm{~h}$ at room temperature. Biotinylated polyclonal rabbit anti-human IL6 was bound to captured human IL-6. Streptavidin-peroxidase conjugate was bound to the biotinylated antibody and reacted with the substrate Tetramethylbenzidine (TMB). The enzyme reaction was stopped by the addition of $1 \mathrm{M} \mathrm{H}_{2} \mathrm{SO}_{4}$. Spectrophotometry was performed at $450 \mathrm{~nm}$.

\subsubsection{TNF $\alpha$ ELISA}

A 96-well microplate (Greiner, 655061) was coated overnight at $4{ }^{\circ} \mathrm{C}$ with mouse anti-human TNF $\alpha$ (61E71; Celltech). rHu TNF- $\alpha$ was used for standard titration curve. Standard and samples were incubated for $1 \mathrm{~h}$ at room temperature. Polyclonal rabbit anti-human TNF- $\alpha$ was bound to captured human TNF- $\alpha$. Goat anti rabbit peroxidase (IgG HRP Jackson Immuno Research) was bound to the secondary antibody and reacted with TMB. The enzyme reaction was stopped by the addition of $1 \mathrm{M} \mathrm{H}_{2} \mathrm{SO}_{4}$. Spectrophotometry was performed at $450 \mathrm{~nm}$.

\subsection{Follow-up}

Patients were evaluated in the outpatient clinic ten days, six weeks and three months postoperatively. Follow up in this subgroup was ended three months after surgery. Assessment of seroma and its sequelae in the outpatient clinic was always performed by a breast surgeon that did not perform the surgery. Special attention was given to the presence of clinical seroma, (surgical skin) infection or the need for seroma aspiration. This information was duly recorded in patients' medical charts.

\subsection{Outcome measures}

1. Seroma: a breast surgeon clinically assessed the presence of seroma. A patient was considered to have seroma if there was a swollen lump or fluid collection under the skin flaps.

2. Seroma aspiration: there were strict criteria for seroma aspiration. The need for seroma aspiration was always assessed by a breast surgeon in the breast clinic. The mere presence of seroma did not warrant seroma aspiration. Seroma aspirations were performed if A) wound healing was at risk due to seroma (wound break down, seroma leakage, necrosis), B) if there was discomfort or pain caused by large amounts of seroma, characterised by tenseness of the skin or C) if there was contaminated/infected seroma and aspiration was necessary to treat infection. All patients undergoing seroma aspiration due to infection were also treated with a 1-week course of amoxicillin/clavulanate $500 / 125 \mathrm{mg}$, three times daily.

3. Infection: surgical site infection (SSI) was defined as redness, pain, heat or swelling at the site of the incision or by the drainage of pus. Infection rate was measured by A) the need for antibiotics, B) seroma aspiration due to infection or $\mathrm{C}$ ) surgical drainage during the first three postoperative months.

\subsection{Statistics}

Statistical analyses were performed using SPSS, version 21 (IBM Corporation, Armonk, NY, USA). Patient characteristics that are continuous variables are presented as means with standard deviations; categorical characteristics are presented as percentages. Continuous variables were compared between study groups with one-way analysis of variance (ANOVA). Categorical variables were compared between study groups with Pearson's Chi-squared test. Linear regression analysis was performed to assess the association between baseline demographics and IL- 6 levels. To analyze the association between IL- 6 and the presence of seroma and seroma related complications, binary logistic
Table 1

Linear regression IL-6 and baseline demographics. * ${ }^{*} \mathrm{p}<0.05$.

\begin{tabular}{llll}
\hline Parameter & $\begin{array}{l}\text { Regression } \\
\text { coefficient }\end{array}$ & CI (95\%) & Significance \\
\hline Age & -0.086 & $-0.02-0.20$ & 0.196 \\
Comorbidity (CI) & 0.016 & $-0.00-0.04$ & 0.112 \\
Neoadjuvant chemotherapy & -0.003 & $-0.01-0.00$ & 0.097 \\
Anticoagulants & -.0001 & $-0.01-0.00$ & 0.566 \\
Smoking & 0.000 & $-0.00-0.00$ & 0.922 \\
BMI & 0.084 & $0.04-0.13$ & $\mathbf{0 . 0 0 1 *}$ \\
Type of operation & 0.000 & $-0.01-0.01$ & 0.966 \\
OR time & 0.088 & $-0.11-0.28$ & 0.361 \\
Bloodloss & 0.050 & $-0.51-0.61$ & 0.856 \\
Wound surface & 0.084 & $-0.15-0.32$ & 0.464 \\
Randomization group & -0.003 & $-0.01-0.01$ & 0.492 \\
Drain time & -0.014 & $-0.03-0.00$ & 0.075 \\
Drain output & -2.706 & $-6.29-0.88$ & 0.134 \\
Axillary lymph node & -0.001 & $-0.01-0.00$ & 0.617 \\
$\quad$ clearance & & & \\
Specimen weight & 5.014 & $1.81-8.22$ & $\mathbf{0 . 0 0 3 *}$ \\
\hline
\end{tabular}

regression analysis was performed. A p-value $\leq 0.05$ was considered to indicate statistical significance. The association between IL- 6 and the presence of seroma was subsequently adjusted for BMI and weight of the resected surgical specimen.

\section{Results}

Forty consecutive patients undergoing mastectomy and spending the first postoperative night in hospital in a short time frame within the study, were included. Characteristics of these patients at baseline are shown in Table 1.

Baseline demographics associated with IL- 6 were identified by linear regression analysis. BMI $(p=0.001)$ and weight of the resected surgical specimen $(\mathrm{p}=0.003)$ were associated with higher IL-6 levels in seroma on the first postoperative day after mastectomy (Table 1). There was a high correlation between BMI and weight of the resected specimen (Pearson correlation coefficient 0.805, 2-tailed significance, $\mathrm{p}<0.001$ ). The wound surface was considered to be shaped like a horizontal diamond and was calculated from the measurements of the skin flaps (from medial to lateral and from cranial to caudal). IL-6 levels were not significantly associated with the calculated wound surface $(\mathrm{p}=0.464)$. Binary logistic regression was used to assess the association between IL- 6 and postoperative complications. Remarkably, higher IL-6 levels were associated with significantly less clinical seroma three months after surgery (OR 0.952 [0.90-0.99], $(\mathrm{p}=0.027)$ ) Table 2. Fig. 1 depicts an error bar for seroma formation at three months in relation to the level of IL- 6 in seroma. The association between IL- 6 and the presence of seroma at three months was subsequently adjusted for BMI and weight of the resected surgical specimen and revealed similar

Table 2

Binary logistic regression IL-6 and outcome. NA = not applicable. OR = odds ratio. ${ }^{*}=\mathrm{p}<0.05$.

\begin{tabular}{llll}
\hline Outcome & OR & CI (95\%) & Significance \\
\hline Clinical seroma 10 days & 0.999 & $0.98-1.02$ & 0.947 \\
Seroma aspiration 10 days & NA & NA & NA \\
Infection 10 days & NA & NA & NA \\
Earlier unplanned visit 6 weeks & 0.971 & $0.91-1.04$ & 0.410 \\
Clinical seroma 6 weeks & 0.984 & $0.96-1.01$ & 0.141 \\
Seroma aspiration 6 weeks & 0.978 & $0.90-1.07$ & 0.627 \\
Infection 6 weeks & 0.972 & $0.92-1.02$ & 0.268 \\
Earlier unplanned visit 6 weeks & 1.00 & $0.98-1.02$ & 0.888 \\
Clinical seroma 3 months & 0.952 & $0.90-0.99$ & $\mathbf{0 . 0 2 7}$ \\
Seroma aspiration 3 months & NA & NA & NA \\
Infection 3 months & 0.981 & $0.90-1.07$ & 0.657 \\
Earlier unplanned visit 3 months & 1.00 & $0.97-1.04$ & 0.791 \\
\hline
\end{tabular}




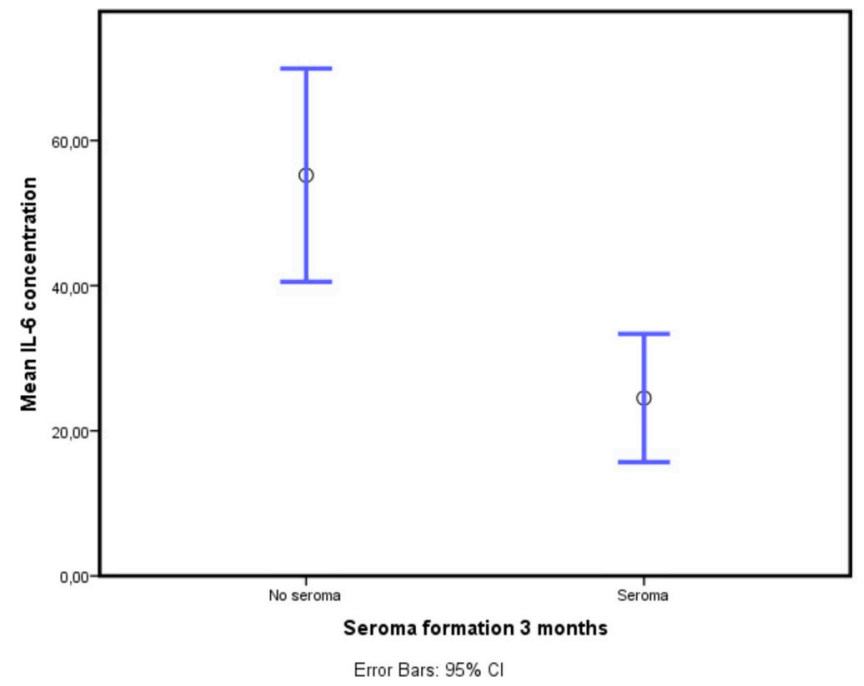

Fig. 1. Plot with error bars expressing mean IL-6 concentration and seroma formation at 3 months.

results, OR 0.94 [0.90-0.99], $\mathrm{p}=0.024$. No seroma related complications were associated with IL-6 levels in seroma fluid.

Thirteen patients were treated in the conventional closure group $(\mathrm{CON})$, thirteen in the flap fixation group using sutures (FF-S) and fourteen patients were treated in the flap fixation group using ARTISS tissue glue (FF-G). Baseline characteristics of these patients are represented in Table 3. There were no significant differences in patient demographics between the three groups. Study results, specified per method of closure, are listed in Table 4 . There was a significant difference in mean closure time between the three groups (CON $=14.9 \mathrm{~min}$ (range 5-25), FF-S $=24.8 \mathrm{~min}$ (range 13-37), FF$\mathrm{G}=15.8 \mathrm{~min}$ (range $12-32$ ), $\mathrm{p}<0.001$ ). The mean total drain production was significantly higher in the conventional closure group $(\mathrm{CON}=522 \mathrm{ml}$ (range 50-1575), FF-S $=174 \mathrm{ml}$ (range 25-505), FF$\mathrm{G}=178 \mathrm{ml}$ (range $5-1080$ ), $\mathrm{p}=0.037$ ). The presence of seroma six weeks after surgery was significantly reduced in the flap fixation groups (CON $=69.2 \%$, FF-S $=7.7 \%$ and FF-G $35.7 \%, \mathrm{p}<0.001$ ). There was a strong tendency towards fewer seroma aspirations in the flap fixation groups $(\mathrm{CON}=15.4 \%$, FF-S and FF-G $0 \%, \mathrm{p}=0,064)$. Patients undergoing conventional wound closure had significantly more seroma formation three months after surgery compared to the other groups $(\mathrm{CON}=46.2 \%, \mathrm{FF}-\mathrm{G}=0 \%, \mathrm{FF}-\mathrm{S}=28.6 \%, \mathrm{p}=0.008)$.

Seroma IL- 6 concentrations on the first post-operative day were not significantly different between the three groups $(\mathrm{CON}=54.21 \mathrm{ng} / \mathrm{ml}$, FF-S $=47.71 \mathrm{ng} / \mathrm{ml}, \mathrm{FF}-\mathrm{G}=44.58 \mathrm{ng} / \mathrm{ml}, \mathrm{p}=0.785)$. Fig. 2 depicts an error bar per group (CON, FF-S, FF-G) in relation to the level of IL-6 in seroma. TNF-alpha concentrations were not detectable in the seroma samples; the concentration of all samples was below the minimally detectable value of $39 \mathrm{ng} / \mathrm{ml}$. The occurrence of surgical site infections (SSI) showed no significant differences at any given time during follow up.

\section{Discussion}

Preventing seroma formation and its complications after mastectomy remains challenging. Flap fixation has been shown to reduce seroma formation and its sequelae in patients undergoing mastectomy [13]. In the literature, several descriptive studies can been found describing the levels of pro-inflammatory cytokines and matrix metalloproteinases in seroma of patients after mastectomy [21-23,26]. In a study by Szecsi et al. a broad spectrum of cytokines were measured in the seroma fluid of 42 patients after mastectomy. Very high levels of IL6 and IL-8 were detected in seroma, however, these levels did not predict the cause of seroma formation [27]. No studies, however, have been performed on the association between pro-inflammatory cytokine levels and seroma related complications after mastectomy.

$\mathrm{BMI}$ and weight of the resected surgical specimen were all significantly associated with the level of IL- 6 on day 1 . A higher BMI and larger breast size (larger bust line and larger total breast area) have been shown to be correlated [28]. If the extent of tissue damage is more extensive in women with larger breasts, higher levels of IL-6 could be accounted for in these patients. It remains surprising that the calculated wound surface was not related to the IL- 6 levels. The wound surface corresponds with the surface of the skin flaps and it would be reasonable to assume that larger skin flaps are directly related to extent of surgical dissection. A possible explanation could be that in patients with a larger bust size, more breast tissue is removed but with a much smaller effect on the extent of the skin flaps. In a study published on patients receiving neoadjuvant chemotherapy for locally advanced breast cancer, serum IL-6 levels were significantly higher before, during and after termination of chemotherapy. This demonstrates a higher pro-inflammatory cytokine release in these patients [29]. In our group of patients there was however no clear association between neoadjuvant chemotherapy and IL-6 ( $\mathrm{p}=0.097)$. Surprisingly, higher IL-6 levels were associated with significantly less clinical seroma three months after surgery. This seems to be the most important finding in this study. A higher level of IL- 6 one day postoperatively is directly related to less long-term seroma formation. In this respect one could conclude that higher IL-6 levels are predictive of less long-term seroma in mastectomy patients. This is in contrast to all reports currently available in the scientific literature. All studies to date have demonstrated that higher IL-6 levels in seroma are related to more wound seroma. The induced inflammatory response after mastectomy releases wound repair cytokines such as IL-6, in turn promoting seroma formation [27]. No plausible explanation could be found for this surprising finding in this study. In this relatively small group of patients there was no association between IL- 6 and seroma related complications.

TNF- $\alpha$ was not detectable in any of the seroma samples as concentrations were too low to be detected by the analytic method used $(<39 \mathrm{pg} / \mathrm{ml})$ on the first postoperative day after mastectomy. A study published by Chow et al. evaluated 29 patients undergoing mastectomy with IL- 6 and TNF- $\alpha$ sampling from drained seroma on day 1, 2 and 5 . TNF- $\alpha$ levels were low on day 1 , showing a progressive rise on day 5 . These results indicate that IL- 6 may be a main cytokine in the early stage, whereas TNF- $\alpha$ may be mainly involved in the later stage of wound healing [21]. As all samples were collected from drained fluid on day 1 , TNF- $\alpha$ was not detectable. Only nine out of forty patients had a drain in situ on day 5 , making measurement of TNF- $\alpha$ impossible with our current drain policy.

IL- 6 levels in seroma were not significantly different between the three groups (flap fixation versus conventional wound closure). This could be explained by the fact that the extent of tissue damage was

Table 3

Patient demographics. Continuous variables are presented as means \pm SD. Categorical variables in percentages.

\begin{tabular}{llll}
\hline Demographics & Conventional & FF- sutures & FF-glue \\
\hline Number of patients & 13 & 13 & 14 \\
Age (years) & $67.2( \pm 12.2)$ & $70.2( \pm 11.5)$ & $68.9( \pm 13.7)$ \\
Comorbidity (CI) & $4.5( \pm 2.0)$ & $5.0( \pm 2.2)$ & $5.2( \pm 2.7)$ \\
Anticoagulant drugs (yes) & $3(23.1 \%)$ & $2(15.4 \%)$ & $4(28.6 \%)$ \\
Smoking (yes) & $0 \%$ & $3(23.1 \%)$ & $1(7.2 \%)$ \\
BMI (kg/m2) & $29.0( \pm 7.2)$ & $27.0( \pm 4.6)$ & $28.0( \pm 5.6)$ \\
Bloodloss (ml) & $78( \pm 48)$ & $68( \pm 49)$ & $91( \pm 79)$ \\
Neoadjuvant chemotherapy (yes) & $4(30.8 \%)$ & $2(15.4 \%)$ & $3(21.4 \%)$ \\
Axillary clearance (yes) & $7(53.8 \%)$ & $3(23.1 \%)$ & $6(42.9 \%)$ \\
Radiotherapy (yes) & $6(46.2 \%)$ & $4(30.8 \%)$ & $3(21.4 \%)$ \\
\hline
\end{tabular}


Table 4

Outcome per group. Continuous variables are presented as means $\pm \mathrm{SD}$, one-way ANOVA. Categorical variables in percentages. * $=\mathrm{p}<0.05$.

\begin{tabular}{|c|c|c|c|c|}
\hline Item & Conventional & $\mathrm{FF}-$ sutures & FF-glue & P-value \\
\hline Operative time (min) & $94.2( \pm 20.5)$ & $88.3( \pm 14.9)$ & $96.3( \pm 27.0)$ & 0.615 \\
\hline Closure time (min) & $14.9( \pm 5.6)$ & $24.8( \pm 6.0)$ & $15.8( \pm 5.5)$ & $<0.001 *$ \\
\hline Specimen weight (grams) & $991(477)$ & $796(304)$ & $825(357)$ & 0.422 \\
\hline Total drain production (ml) & $522(510)$ & $174(186)$ & $178(286)$ & $0.037^{*}$ \\
\hline Seroma 10 days (yes) & $76.9 \%$ & $53.8 \%$ & $78.6 \%$ & 0.065 \\
\hline Seroma aspiration 10 days (yes) & 0 & 0 & 0 & - \\
\hline SSI 10 days (yes) & 0 & 0 & 0 & - \\
\hline Seroma 6 weeks (yes) & $9(69.2 \%)$ & $1(7.7 \%)$ & $5(35.7 \%)$ & $<0.001 *$ \\
\hline Seroma aspiration 6 weeks (yes) & $2(15.4 \%)$ & 0 & 0 & 0.064 \\
\hline SSI 6 weeks (yes) & $2(15.4 \%)$ & 0 & $2(14.3 \%)$ & 0.264 \\
\hline Seroma 3 months (yes) & $6(46.2 \%)$ & 0 & $4(28.6 \%)$ & $0.008^{*}$ \\
\hline Seroma aspiration 3 months (yes) & 0 & 0 & 0 & - \\
\hline SSI 3 months (yes) & 0 & 0 & $1(7.1 \%)$ & 0.430 \\
\hline IL-6 (ng/ml) & $54.21( \pm 48.59)$ & $47.71( \pm 29.59)$ & $44.58( \pm 27.83)$ & 0.785 \\
\hline
\end{tabular}

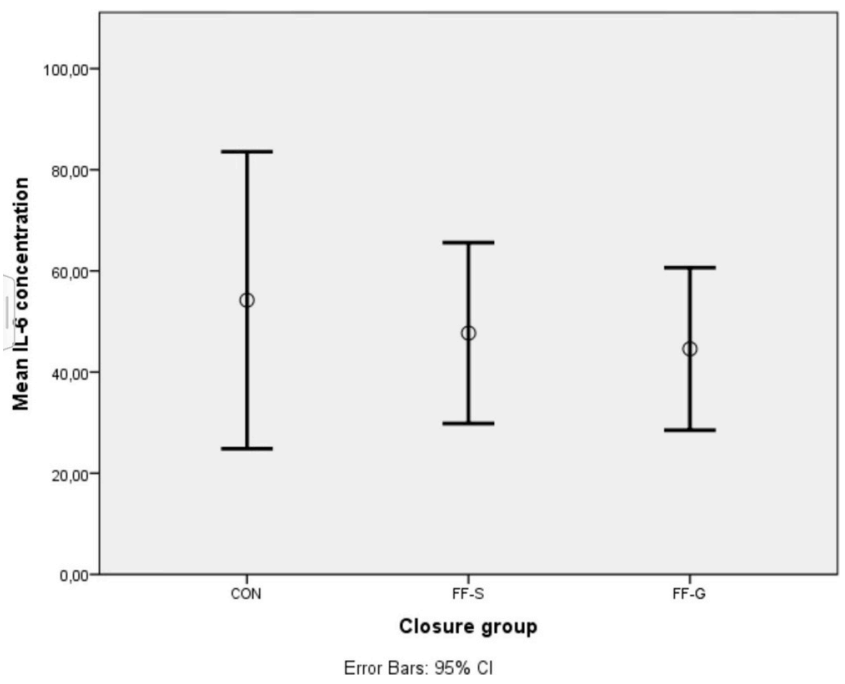

Fig. 2. Error bar depicting the relation of IL-6 levels in seroma per method of wound closure group (CON, FF-S, FF-G).

similar in all groups. Wound surface, percentage of patients undergoing axillary clearance or neoadjuvant chemotherapy were not significantly different between the groups. The final results of the SAM-trial are being awaited. This is a well-powered study in which 336 patients will be included. This will provide us with further information on the true value of flap fixation in mastectomy patients with regard to seroma and seroma related complications as well as cost-effectiveness and quality of life.

\section{Conclusion}

Higher interleukin- 6 levels are associated with less clinical seroma formation three months after surgery but there is no apparent association between IL- 6 and seroma related complications up to three months after mastectomy. Higher IL- 6 levels in this group of patients seem indicative of less long-term seroma. Flap fixation does not seem to influence postoperative levels of IL- 6 in seroma fluid on the first day after mastectomy.

\section{Ethics approval and consent to participate}

Written informed consent was obtained from all trial participants. This trial was approved by the hospitals' joint medical ethical committee (METC-Zuyd, 14-T-21, 2 June 2014).

\section{Consent for publication}

Not applicable.

\section{Availability of data and materials}

The datasets used and/or analyzed during the current study are available from the corresponding author on reasonable request.

\section{Conflicts of interest}

The authors declare that they have no competing interests.

\section{Funding}

No external funding was received for this study.

\section{Trial registration}

Trial registration: NCT03305757. Registered 10 October 2017 Retrospectively NCT03305757. registered, https://clinicaltrials.gov/ct2/show/

\section{CRediT authorship contribution statement}

J. van Bastelaar: Conceptualization, Data curation, Formal analysis, Investigation, Methodology. R. Granzier: Data curation, Formal analysis, Project administration. L.M. van Roozendaal: Data curation, Formal analysis, Project administration. S.M.J. van Kuijk: Investigation, Methodology, Validation. A.V. Lerut: Investigation, Project administration. G. Beets: Supervision. M. Hadfoune: Validation, Visualization. S. Olde Damink: Supervision. Y.L.J. Vissers: Conceptualization, Formal analysis, Supervision.

\section{Acknowledgements}

The authors gratefully acknowledge the contributions of the nurse practitioners and breast care nurses in all the breast clinics. Conducting this study would have been impossible without their contributions.

\section{Appendix A. Supplementary data}

Supplementary data to this article can be found online at https:// doi.org/10.1016/j.suronc.2018.11.001.

\section{References}

[1] K. Tadych, et al., Postmastectomy seromas and wound drainage, Surg. Gynecol. 
Obstet. 165 (6) (1987) 483-487.

[2] S. Kumar, et al., Post-mastectomy seroma: a new look into the aetiology of an old problem, J. R. Coll. Surg. Edinb. 40 (1995) 292-294.

[3] L.M. Almond, et al., Flap anchoring following primary breast cancer surgery facilitates early hospital discharge and reduces costs, Breast Care 5 (2) (2010) 97-101.

[4] L.M. Almond, L. Khodaverdi, B. Kumar, E.C. Coveney, Flap anchoring following primary breast cancer surgery facilitates early hospital discharge and reduces costs, Breast Care 5 (2) (2010) 97-101.

[5] M.A. Sakkary, et al., The value of mastectomy flap fixation in reducing fluid drainage and seroma formation in breast cancer patients, World J. Surg. Oncol. 10 (2012) 8 .

[6] B. Ten Wolde, et al., Quilting prevents seroma formation following breast cancer surgery: closing the dead space by quilting prevents seroma following axillary lymph node dissection and mastectomy, Ann. Surg. Oncol. 21 (2014) 802-807.

[7] L. Ouldamer, et al., Quilting suture of mastectomy dead space compared with conventional closure with drain, Ann. Surg. Oncol. 22 (2015) 4233-4240.

[8] A. Khater, et al., Evaluation of the quilting technique for reduction of postmastectomy seroma: a randomized controlled study, Int. J. Breast Canc. 2015 (2015) 287398.

[9] C. Mazouni, et al., Quilting Sutures Reduce Seroma in Mastectomy vol. 15, (2015), pp. 289-293 4.

[10] van Bastelaar, et al., Flap fixation reduces seroma in patients undergoing mastectomy: a significant implication for clinical practice, World J. Surg. Oncol. 14 (2016 Mar 8) 66.

[11] C. Eichler, et al., Flap adhesion and effect on postoperative complication rates using Tissuglu ${ }^{\circledast}$ in mastectomy patients, Breast Canc. 23 (2016) 486-490.

[12] Van Bastelaar, et al., Flap fixation using tissue glue or sutures appears to reduce seroma aspiration after mastectomy for breast cancer, Clin. Breast Canc. 17 (4) (2017 July) 316-321.

[13] Van Bastelaar, et al., A systematic review of flap fixation techniques in reducing seroma formation and its sequelae after mastectomy, Breast Canc. Res. Treat. (2017 Oct 16), https://doi.org/10.1007/s10549-017-4540-x.

[14] K.A. Porter, et al., Electrocautery as a factor in seroma formation following mas tectomy, Am. J. Surg. 176 (1998) 8-11.

[15] W.L. Olszewski, Collection and physiological measurements of peripheral lymph and interstitial fluid in man, Lymphology 10 (1997) 137-145.

[16] W.L. Olszewski, et al., Immune cell traffic from blood through the normal skin to lymphatics, Clin. Dermatol. 13 (1995) 473-483.

[17] P. Andrades, et al., Composition of postabdominoplasty seroma, Aesthet. Plast. Surg. 31 (2007) 514-810.

[18] S.Y. Boostrom, et al., Incidence of clinically significant seroma after breast and axillary surgery, J. Am. Coll. Surg. 208 (1) (2009) 148-150.

[19] G. Henry, et al., Inflammatory mediators in wound healing, Surg. Clin. 83 (2003) 483-507.

[20] W. Grellner, et al., Quantitative analysis of proinflammatory cytokines (IL-1beta, IL6, TNF-alpha) in human skin wounds, Forensic Sci. Int. 113 (2000) 251-264.

[21] L.W.C. Chow, et al., The study of cytokine dynamics at the operation site after mastectomy, Wound Repair Regen. 11 (5) (2003) 326-330.

[22] W.T.Y. Loo, et al., Pro-inflammatory cytokine, matrix metalloproteinases and TIMP1 are involved in wound healing after mastectomy in invasive breast cancer patients, Biomed. Pharmacother. 61 (9) (2007) 548-552.

[23] E.A. Baker, et al., Temporal and quantitative profiles of growth factors and metalloproteinases in acute wound fluid after mastectomy, Wound Repair Regen. 16 (1) (2008) 95-101.

[24] K.B. Yilmaz, et al., Comparing scalpel, electrocautery and ultrasonic dissector ef fects: the impact on wound complications and pro-inflammatory cytokine levels in wound fluid from mastectomy patients, J Breast Cancer 14 (1) (2011) 58-63.

[25] Inc. BI. ARTISS [Fibrin Sealant Human], Baxter Healthcare Corporation, Deerfield, 2011.

[26] E. Montalto, et al., Seroma fluid subsequent to axillary lymph node dissection for breast cancer derives from an accumulation of afferent fluid, Immunol. Lett. 131 (1) (2010) 67-72.

[27] P.B. Szecsi, et al., Seroma production after breast cancer surgery has a pro-inflammatory component, Open Breast Canc. J. 4 (2012) 11-17.

[28] L.Y. Lim, et al., Determinants of breast size in Asian women, Sci. Rep. 8 (1) (2018 19) 1201, https://doi.org/10.1038/s41598-018-19437-4.

[29] M.F.C.J. Paz, et al., Assessment of chemotherapy on various biochemical markers in breast cancer patients, J. Cell. Biochem. (2017), https://doi.org/10.1002/jcb. 26487. 